\section{Poor nations claim victory at climate talks}

Negotiators at climate talks in Bali on Monday agreed on the details of a fund to help the most vulnerable nations adapt to climate change.

The adaptation fund, generated through a $2 \%$ levy on transactions between parties participating in the Kyoto Protocol's emissions-trading mechanism, has been accumulating for several years. But it has not yet been activated because countries could not agree on which body would approve the projects to be included in the scheme. They have now settled on the United Nation's Framework Convention on Climate Change.

The decision is a victory for poor countries and small island states, which had argued that the fund, currently administered by a multilateral environmental-funding agency based in Washington DC, should have its own board and governance system. So far, the emissions-trading mechanism has generated US\$67 million for adaptation measures.

Meanwhile, scientists in Bali called on governments to stabilize global emissions well below 450 parts per million of carbondioxide equivalents in the long term, their most concrete recommendation to politicians so far. Higher concentrations would mean that climate change may become unmanageable, they warned in a formal declaration issued on 6 December.

\section{'Heated bidding' for rocket scientist's thesis}

A formerly top-secret document produced by controversial rocket scientist Wernher von Braun for his $\mathrm{PhD}$ dissertation sold for US $\$ 33,000$ at auction in New York last week.

The 166-page thesis, Design, Theoretical and Experimental Contributions to the Problem of the Liquid-Fuel Rocket,

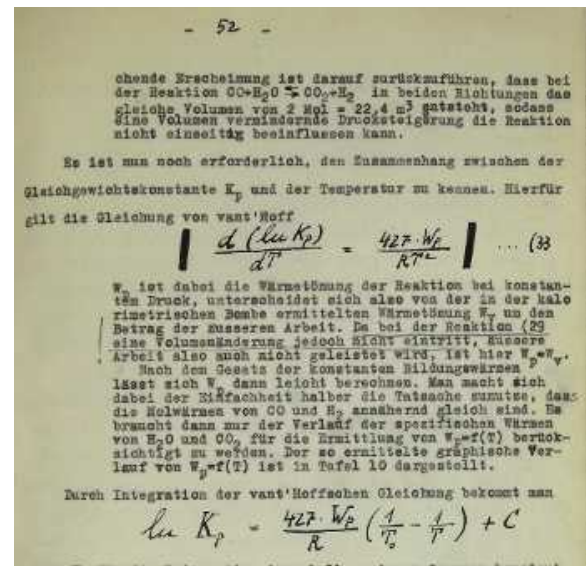

Wernher von Braun's PhD thesis sold for $\$ 33,000$. was classified as 'top secret' by the Nazi government and, although written in 1934, was not published until 1960.

After working on rockets for the Nazis during the Second World War - his exact motivations are still debated - von Braun was spirited to the United States to work on missiles. He later became the first director of NASA's Marshall Space Flight Center in Huntsville, Alabama.

After what the auction house Bonhams describes as "heated bidding", the thesis sold for $\$ 3,000$ more than its original estimate.

\section{Switzerland launches systems-biology initiative}

One of the world's largest systems-biology research consortiums, known as SystemsX, has been launched in Switzerland.

The federal government has committed 200 million Swiss francs (US\$177 million) to the project, half of which will support technology platforms at an ETH Zurich department based in Basel, which is also home to several large drug and chemical firms including Novartis and Roche.

The rest of the money will fund researchers at eleven universities and research institutes - or industry bodies - which will have to match those funds with their own money. 
The Swiss National Science Foundation will supervise the scientific quality of the initiative, with help from international experts. This is a first for the granting agency, which has not previously been involved in the quality control of projects it does not fund itself.

\section{US politicians push for food-safety funding boost}

Twenty-three US senators are calling on President George W. Bush to boost funding for food-safety oversight in 2009. In a 6 December letter to Bush, the bipartisan group complained that the budget of the Food and Drug Administration (FDA) does not reflect its "critical" and growing role.

They noted, for instance, that the value of US agricultural imports had grown by $40 \%$ between 2003 and 2006, yet between 2004 and 2007, the number of employees dedicated to food safety at the FDA fell by $15 \%$ to 2,613. In February, Bush proposed increasing the agency's food-safety budget by $\$ 10.5$ million, to $\$ 467$ million. Congress has yet to approve the spending bill.

The letter comes on the heels of a highly critical report on 29 November from the FDA's scientific advisory board. It said that the \$1.9-billion agency cannot fulfil its mission because of the erosion and inadequacy of its scientific base and information-technology infrastucture.

\section{Private funds raise hopes for giant telescope}

Plans to build the world's largest optical telescope were jump-started with a 5 December announcement that a foundation set up by Intel co-founder Gordon Moore and his wife Betty had given the California Institute of Technology and the University of California \$200 million.

The two universities will also put in $\$ 100$ million for the billion-dollar project, called the Thirty Meter Telescope (TMT).

The gift puts the TMT ahead of two other planned mega-telescopes - the

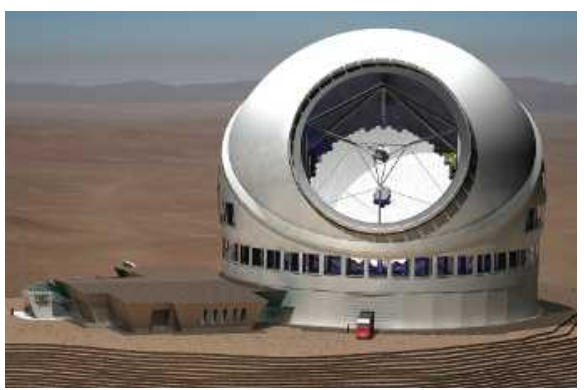

The Thirty Meter Telescope will have $\mathbf{4 9 2}$ mirrors.
Giant Magellan Telescope, a 24.5-metre telescope led by a consortium including the Carnegie Institution of Washington, and the Extremely Large Telescope, a 42-metre observatory planned by the European Southern Observatory. The TMT's 492 hexagonal mirrors will stretch for $\mathbf{3 0}$ metres, and the device is expected to achieve a better resolution than that of the Hubble Space Telescope. A final design is expected in 2009.

\section{Hackers steal personal data from US laboratories}

The Oak Ridge National Laboratory (ORNL) in Tennessee has warned some 12,000 people that their personal data may have been stolen as part of a "sophisticated cyber attack".

Hackers sent lab employees e-mails that seemed legitimate but contained attachments that, when opened, gave the hackers access to their computers. The 'phishing' scheme apparently allowed the hackers to download personal information about people visiting the laboratory between 1990 and 2004.

\section{Correction}

The legend to our graphic ' $\mathrm{CO}_{2}$ emissions 19902006' (Nature 447, 1038; 2007) erroneously gave $\mathrm{CO}_{2}$ intensity in tonnes per thousand US\$ GDP. It should have been tonnes per million US\$ GDP. 